\title{
Can malaria vector control accelerate the interruption of lymphatic filariasis transmission in Africa; capturing a window of opportunity?
}

Louise A Kelly-Hope*, David H Molyneux and Moses J Bockarie

\begin{abstract}
Background: The Global Programme to Eliminate Lymphatic Filariasis (GPELF) was launched in 2000, and nearly all endemic countries in the Americas, Eastern Mediterranean and Asia-Pacific regions have now initiated the WHO recommended mass drug administration (MDA) campaign to interrupt transmission of the parasite. However, nearly $50 \%$ of the LF endemic countries in Africa are yet to implement the GPELF MDA strategy, which does not include vector control. Nevertheless, the recent scale up in insecticide treated /long lasting nets (ITNS/LLINs) and indoor residual spraying (IRS) for malaria control in Africa may significantly impact LF transmission because the parasite is transmitted mainly by Anopheles mosquitoes. This study examined the magnitude, geographical extent and potential impact of vector control in the 17 African countries that are yet to or have only recently started MDA.

Methods: National data on mosquito bed nets, ITNs/LLINs and IRS were obtained from published literature, national reports, surveys and datasets from public sources such as Demographic Health Surveys, Malaria Indicator Surveys, Multiple Indicator Cluster Surveys, Malaria Report, Roll Back Malaria and President's Malaria Initiative websites. The type, number and distribution of interventions were summarised and mapped at sub-national level. and compared with known or potential LF distributions, and those which may be co-endemic with Loa loa and MDA is contraindicated.
\end{abstract}

Results: Analyses found that vector control activities had increased significantly since 2005, with a three-fold increase in ITN ownership and IRS coverage. However, coverage varied dramatically across the 17 countries; some regions reported $>70 \%$ ITNs ownership and regular IRS activity, while others had no coverage in remote rural populations where the risk of LF was potentially high and co-endemic with high risk L.loa.

Conclusions: Despite many African countries being slow to initiate MDA for LF, the continued commitment and global financial support for NTDs, and the concurrent expansion of vector control activities for malaria, is promising. It is not beyond the capacity of GPELF to reach its target of global LF elimination by 2020, but monitoring and evaluating the impact of these activities over the next decade will be critical to its success.

Keywords: Lymphatic filariasis, Mass drug administration, Vector control, Long-lasting insecticidal nets, LLINs, Indoor residual spraying, IRS, Anopheles, Mosquitoes, Malaria

\footnotetext{
* Correspondence: L.Kelly-Hope@liverpool.ac.uk

Centre for Neglected Tropical Diseases, Liverpool School of Tropical

Medicine, Pembroke Place, Liverpool L3 5QA, UK
} 


\section{Background}

The Global Programme to Eliminate Lymphatic Filariasis (GPELF) has made remarkable progress since its inception in 2000, and is hailed to be the most rapidly expanding global health programme in history $[1,2]$. Nearly all 39 endemic countries in the Americas, Eastern Mediterranean and Asia-Pacific regions have initiated or finished the World Health Organization (WHO) recommended mass drug administration (MDA) campaign to interrupt transmission of the two main parasites, Wuchereria bancrofti and/or Brugia malayi with significant scale-up in drug distributions and reductions in disease burden being demonstrated $[1,2]$.

This progress is promising for GPELF and its goal of LF elimination by 2020 [1]. However, for all countries to fully benefit from this global effort, it must address the slow progress in Africa where half of the 34 endemic countries have not or have only just started to implement the GPELF intervention strategy for LF elimination, which does not promote vector control, despite the suggestion of the need to link malaria and LF activities for mutual benefit [3-5], and the widespread evidence of the value of vector control in the control/ elimination of LF [6,7].

The African continent has a large burden of LF, which is caused by the parasite $W$. bancrofti and predominantly transmitted by Anopheles mosquitoes in rural areas and by Culex in urban and coastal areas of East Africa [7-12]. While many countries have started MDA and made steady progress over the past decade, at the half way mark of GPELF in $2010[1,13]$, there were still 17 endemic countries that had not started MDA activities for LF elimination. These countries included Angola, Central Africa Republic (CAR), Chad, Congo, Democratic Republic of Congo (DRC), Equatorial Guinea, Eritrea, Gabon, The Gambia, Guinea, Guinea-Bissau, Liberia, São Tomé and Príncipe, Zambia, Zimbabwe and the new Sudan/South Sudan [1].

There are several factors that have potentially impacted on the progress of these countries and their ability to fully establish their LF Programme, and launch or scale-up MDA activities. Many of these countries are among the poorest in the world according to the United Nations Human Development Index (HDI), with over half the countries among the 20 least developed countries in the world (i.e. CAR, Chad, DRC, Eritrea, The Gambia, Guinea, Guinea-Bissau, Liberia, Sudan/South Sudan, Zimbabwe) [14]. Many are conflict or post-conflict countries with fragile health systems, inadequate transport infrastructure, populations which are difficult to access and with a high number of internally displaced people [14,15]. Additionally, half of the countries are co-endemic with Loa loa, another filarial parasite that can cause severe adverse events (SAEs) after treatment with ivermectin [16-18]. This is a significant impediment for countries in West and Central Africa, particularly in DRC where both diseases are considered to be highly endemic [19].

These challenges pose major barriers for national LF programmes. Whilst twice yearly treatment of albendazole alone has been recommended as an alternative drug regime in LF/L. loa co-endemic areas where ivermectin cannot be safely used on a mass scale [20], it is imperative that additional strategies such as vector control, and links with large scale malaria programmes are considered, especially as interventions such as insecticide treated and/or long lasting insecticidal nets (ITNs/LLINs) [21] and indoor residual spraying (IRS) [22] for malaria control, have shown to impact LF in a variety of ecological settings where Anopheles are the primary vectors [23-31]. WHO is advocating for integrated vector management (IVM), encouraging better linkages between LF and malaria programmes [32], and has recently developed provisional strategies for interrupting LF in loiasis-endemic areas which involves vector control [18].

The objective of this study was to examine the magnitude and geographical extent of recent deployment of ITNs/ LLINs and IRS activities in 17 African countries to determine the potential additive impact of vector control interventions on LF and their potential contribution to the global goal of LF elimination by 2020 .

\section{Methods}

\section{Data sources}

National data on the population at risk of LF and the $L$. loa co-endemicity status was obtained from the WHO Progress Report [1] for Angola, CAR, Chad, Congo, DRC, Eritrea, Equatorial Guinea, Gabon, The Gambia, Guinea, Guinea Bissau, Liberia, São Tomé and Príncipe, Sudan/South Sudan, Zambia, and Zimbabwe. The African map of LF developed by Lindsay and Thomas [7] was used to highlight the distribution of microfilaria (Mf) prevalence levels of $20-40 \%$, and $>40 \%$ across the continent, specifically in the 17 countries and in relation to L. Loa prevalence. The recent loiasis risk map for Africa defined from extensive field surveys of eye worm history $[16,33,34]$, was used to highlight the distribution of L.loa prevalence levels of $20-40 \%$, and $>40 \%$ including the risk of SAEs. The LF and L. Loa maps were imported and digitised in the geographical information system software ArcGIS 10 (ESRI, Redlands, CA) to define the specific prevalence distributions, examine the extent of geographical overlap and to identify areas that would benefit from vector control.

National and sub-national data collected between 2000 and 2010 with specific geographical information on mosquito bed nets, ITNs and IRS were obtained from published literature, national reports, surveys and datasets from public sources including the WHO, Demographic 
Health Surveys (DHS), Malaria Indicator Surveys (MIS), and Multiple Indicator Cluster Surveys (MICS), World Malaria Reports, Roll Back Malaria (RBM) and President's Malaria Initiative (PMI) websites [35-41]. Specifically, household-level data from DHS and MIS cluster surveys $[38,39]$ with information on the geographical coordinates of each cluster (i.e. geo-referenced), were obtained to examine the finer spatial distribution of vector control interventions for malaria relating to household ownership and number of mosquito bed nets, and presence of IRS activities.

\section{National and sub-national analyses}

National data on the percentage of households owning at least one ITN and percentage of IRS coverage between 2000 and 2010 were summarised $[35,36]$. The differences between urban and rural populations and the percentage of households with at least one type of mosquito bed net, at least one ITN and the percentage of children $<5$ years of age who had slept under any net the night prior to the survey were summarised and tabulated for each country based on all DHS, MIS and MICS reports available [38,39]. Sub-national data were based on recent provincial/state reports and survey data available from 2005 and used to create maps using software ArcGIS 10 (ESRI, Redlands, CA). The percentage of households with very low $(<25 \%)$, low $(25-50 \%)$, medium $(50-75 \%)$ and high $(>75 \%)$ coverage of at least one bed net (any type), at least one ITN and the presence of IRS activities were highlighted for each country with the data available. DHS geo-referenced cluster data (latitude and longitude coordinates) in geographically defined areas, with information on vector control activities were also used to map the spatial distributions of bed nets (any type) and IRS activities on a finer scale.

\section{Results}

\section{National data analysis}

The estimated population at risk of LF is summarised in Table 1. Collectively these countries account for more than 100 million people at risk, representing approximately half of the estimated burden across Africa. Geographically, these countries cover vast, often remote, areas of the continent over more than 10 million $\mathrm{km}^{2}$ as shown in Figure 1a. The geographical limits of LF mapped in Figure 1b highlight the widespread nature of the disease with most of the 17 countries highly endemic with Mf prevalence estimates $>40 \%$. The distribution of L. loa was mainly found in Central and West Africa (Figure 1c). In total 8 countries are considered to be co-endemic with $W$. bancrofti and L.loa with the greatest risk of L. loa and SAEs in CAR, Congo, DRC, Equatorial Guinea, Gabon and the new country of South Sudan (Figure 1d).
Data collected from the recent World Malaria Reports $[35,36]$ estimate that the proportion of households owning at least one ITN (based on modeled estimates between 2000 and 2010), had increased three-fold overall since 2005 (Table 1), however, there was great variation between the 17 countries as highlighted in Figure 2a. Between 2000 and 2004, the average national ITN coverage was $10.6 \%$ for all countries and ranged from 1.0 to $58.2 \%$, with the lowest coverage in Guinea 1.0\%, Congo, Liberia and Sudan 2\%, and the highest in The Gambia 24\%, São Tomé and Príncipe 29\% and Eritrea 58\%. Data from between 2005 and 2010, showed the average national ITN coverage was $32.4 \%$ for all countries with a range from 6.2 to $68.7 \%$, with the lowest coverages in Guinea $6.2 \%$, Congo $7.7 \%$ and Chad $7.2 \%$ and the highest in Eritrea 68.7\%, São Tomé and Príncipe 59\%, Zambia 59\% (Table 1, Figure 2a).

Similarly for IRS, the data available in the World Malaria Reports indicate that the proportion of people coverage by IRS differed over time and between countries as shown in Table $1[35,36]$. Overall, there were fewer countries receiving IRS and the coverage was generally low. Between 2000 and 2004, the average national coverage was $6.9 \%$ for the six countries reporting this activity, and coverage ranged from $0.2 \%$ in Angola to $17.3 \%$ in Zambia (Figure 2b). This compared to data between 2005 and 2010, when the average national IRS coverage was $20.7 \%$ for the 10 countries reporting this activity, and ranged from $0.1 \%$ in DRC to 74.3\% in São Tomé and Príncipe.

\section{National urban and rural comparisons}

DHS, MIS [38] and MICS [39] reports indicate that differences between urban and rural populations in relation to the percentage of households with at least one bed net (any type), an ITN and children $<5$ years of age who had slept under any net are shown in Table 2. Overall, the highest coverage rates were found in urban areas except in selected surveys of Angola, Equatorial Guinea, Eritrea, Liberia and Zambia. Similar to data presented in Table 1, coverage rates were generally lower for the period 2000 to 2004 compared with 2005 to 2010. Overall, the majority of countries with data from two different time periods had a two- to three-fold increase in coverage over a 5 to 7 year period.

For the period 2000 to 2004, there were limited data available on the percentage of bed nets (any type) and/or ITNs [38,39], however, there were 10 surveys reporting the percentage of children $<5$ years of age who had slept under any net, highlighting that the lowest coverage was in Angola, Eritrea, DRC and Zambia (urban 10.8- 15.0\%; rural 4.7-11.0\%) and the highest coverage in Guinea Bissau, São Tomé and Príncipe and Chad (urban 57.5 - 74.7\%; rural 18.6 - 63.4\%) (Table 2). The most significant increases in coverage after this period were the percentages of children 
Table 1 Summary of disease data and main vector control interventions 2000 to 2010

\begin{tabular}{|c|c|c|c|c|c|c|}
\hline \multirow{2}{*}{$\begin{array}{l}\text { Country } \\
\text { Angola }\end{array}$} & \multirow{2}{*}{$\begin{array}{l}\text { Risk of LF } \\
12090000\end{array}$} & \multirow{2}{*}{$\begin{array}{c}\text { Loa loa endemic } \\
\text { Yes }\end{array}$} & \multicolumn{2}{|c|}{$\begin{array}{c}\text { Households (\%) at least one ITN } \\
2000-042005-10\end{array}$} & \multicolumn{2}{|c|}{$\begin{array}{l}\text { IRS coverage (\%) } \\
2000-042005-10\end{array}$} \\
\hline & & & 6.0 & 17.7 & 0.2 & 3.6 \\
\hline CAR & 3300000 & Yes & 4.6 & 19.7 & - & - \\
\hline Chad & 7270000 & Yes & 5.2 & 7.2 & - & - \\
\hline Congo & 2600000 & Yes & 1.8 & 7.7 & - & - \\
\hline DRC & 49140000 & Yes & 2.8 & 26.5 & - & 0.1 \\
\hline Equat. Guinea & 420000 & Yes & 2.2 & 30.0 & 8.0 & 32.2 \\
\hline Eritrea & 3577000 & No & 58.2 & 68.7 & 4.5 & 4.6 \\
\hline Gabon & 1290600 & Yes & 1.8 & 41.0 & - & - \\
\hline Gambia & 1200000 & No & 24.2 & 43.2 & - & 35.1 \\
\hline Guinea & 6067135 & No & 1.0 & 6.2 & - & 0.4 \\
\hline Guinea-Bissau & 1311741 & No & 14.6 & 41.2 & - & - \\
\hline Liberia & 3600000 & No & 1.8 & 37.8 & - & - \\
\hline STP* & 410000 & No & 29.4 & 59.0 & - & 74.3 \\
\hline Sudan & - & Yes & 1.8 & 17.7 & 6.9 & 6.7 \\
\hline Zambia & 8780000 & No & 11.2 & 59.0 & 4.4 & 32.0 \\
\hline Zimbabwe & 6000000 & No & 2.8 & 35.3 & 17.3 & 31.1 \\
\hline
\end{tabular}

*STP=São Tomé and Príncipe.

using bed nets in rural areas of The Gambia (35.8\% to $67 \%)$, in São Tomé and Príncipe (28.2\% to $52.3 \%)$ and Zambia (4.7\% to $49.3 \%)$.

For the period 2005 to 2011, countries with the lowest coverage of bed nets (any type) included Zimbabwe and Guinea (urban 27.5 - 34.4\%; rural 12.8 - 26.5\%) with the highest in Congo and Guinea Bissau (urban 81.5 - 82\%; rural 68.2 - 77.8\%) [38,39]. For ITNs, the lowest coverage was in the Congo, Guinea and Zimbabwe (urban 1.0 $11 \%$; rural $0.3-8.0 \%$ ), and the highest in São Tomé and Príncipe and Zambia (urban 52.6 - 69.2\%; rural 52.4 $53.7 \%$ ). Similarly, for children $<5$ years of age who had slept under a bed net [any type], the lowest coverage was in Angola, Guinea and Zimbabwe (urban 15.7 - 19.2\%; rural 3.2 - 22\%) and the highest in Guinea Bissau, The Gambia, and São Tomé and Príncipe (urban 54.6-79.9\%; rural 67.6-70.5\%).

\section{Sub-national mosquito bed net and ITN maps}

Maps of provincial and/or state level coverage were created from the report data $[38,39]$ to highlight the broad distribution of bed nets (any type) and ITNs across Angola, CAR, Congo, DRC, The Gambia, Guinea, Guinea Bissau, Liberia, São Tomé and Príncipe, Zambia and Zimbabwe from survey data obtained between 2005 and 2011 (Figure 3a,b). No recent provincial and/or state level data were available from these data sources for Chad, Equatorial Guinea, Eritrea, Gabon or Sudan.

Overall, higher percentages were found across Congo, Guinea Bissau, The Gambia, Liberia, São Tomé and
Príncipe and Zambia (Figure 3a,b). However, there were some differences between countries, for example, Congo had a higher percentage of bed nets (any type) than all other countries but very low ITNs, whereas Zambia had a relatively high percentage of both interventions (Figure 3a, b). In high risk L.loa countries (Figure 1), there was generally no information available or predominately low percentages of bed nets (any type) and ITNs reported, except in Congo where there was a very high ( $>75 \%)$ percentage of bed net use (any type).

Geo-referenced cluster data with information on the percentage of households with no bed net, one bed net (any type) and two bed nets (any type) were available for six countries including, Angola, DRC, Guinea, Liberia, Zambia, and Zimbabwe [38]. The number of clusters differed for each country, however, the overall trends were similar with a high percentage $(>50 \%)$ of households reporting no ownership of a bed net (Figure $4 a, d)$. There was a lower percentage $(<25 \%)$ of households with one bed net, however, Liberia and Zambia reported higher coverages than the other countries (Figure 4b, e). Very few households in each cluster had two bed nets, with Zambia reporting the highest coverage (Figure 4c, f).

\section{Sub-national IRS data and maps}

Information on IRS activities since 2005 were available for ten countries, including Angola, DRC, Equatorial Guinea, Eritrea, The Gambia, Guinea, Liberia, São Tomé and Príncipe, Zambia, and Zimbabwe. The main sources were WHO, RBM and PMI reports [37,40,41], and DHS 
A Study countries

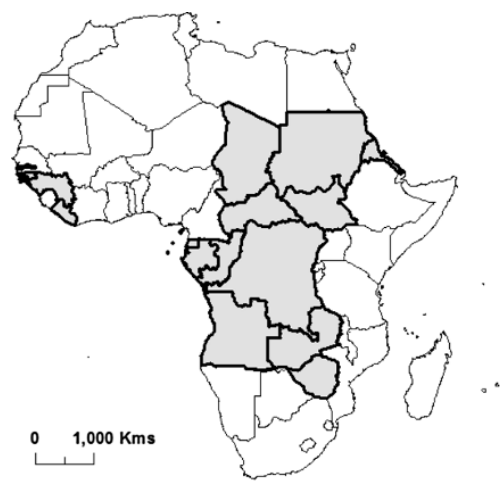

C L. Loa prevalence

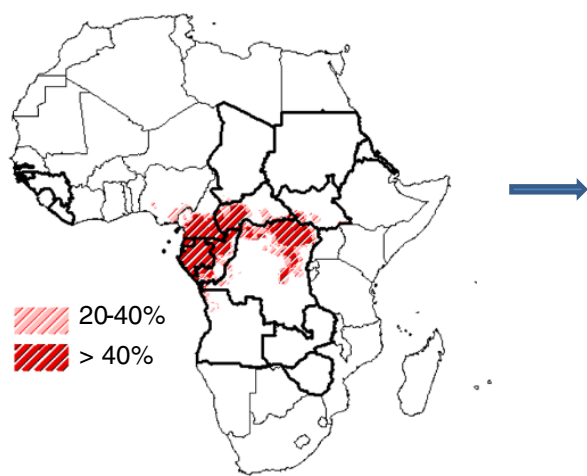

B LF prevalence

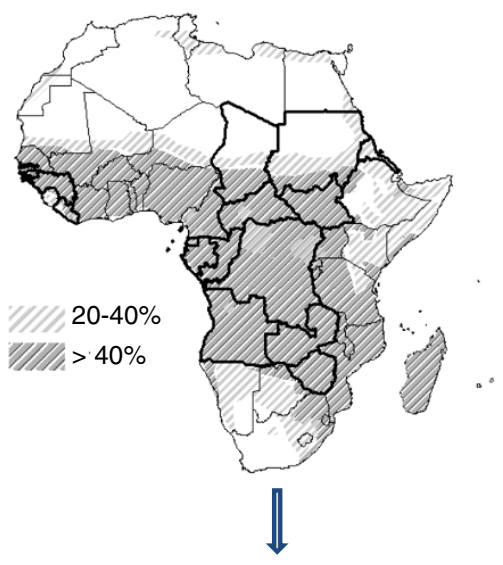

D LF and L. loa co-endemicity

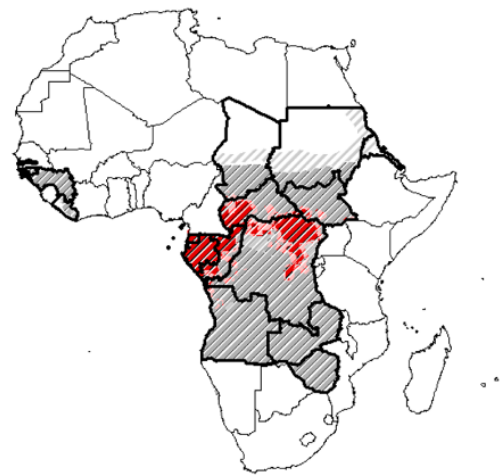

Figure $1 \mathrm{LF}$ and Loa loa prevalence and the extent of co-endemicity in 17 countries. A. Study countries. B. LF prevalence. C. L. loa prevalence. D. LF and L. loa co-endemicity.

reports and geo-referenced cluster data [38], with little or no information available from other sources. There was great variability in the detail of reporting including the population covered, geographical extent of activities and insecticides used, which mainly included pyrethroids (lambdacyhalothrin, alphacypermethrin), and/ or organochlorines (DDT), however, carbamates were also reported in some countries where insecticide resistance had emerged in key vector Anopheles species [41].

Overall, the most extensive IRS activities were reported in Angola, Zambia and Zimbabwe. In Angola, IRS with lambdacyhalothrin was used periodically in selected areas of central and southern provinces since 2006. In Zambia, IRS activities were expanded rapidly from 2004 to reach full geographical coverage using different insecticides in different regions including lambdacyhalothrin, DDT, carbamates, and etofenpox. Similarly, Zimbabwe scaled up IRS activities significantly over the past decade using DDT and lambdacyhalothrin. The DHS geo-referenced cluster data on the percentage of households reporting IRS activities were available for all three countries for the period 2005-2007, and for Angola and Zimbabwe for the years
2010-2011 (Figure 5a, b). Comparison between the different time periods indicated an increase in IRS activities in Angola with six clusters from four provinces reporting $>25 \%$ IRS activities in 2007, compared with 28 clusters from eight provinces in 2011. Zimbabwe had higher coverage overall, and 80 clusters from nine provinces reported $>25 \%$ IRS in 2005, compared with 95 clusters in 2010. In Zambia, 69 clusters from nine provinces reported $>25 \%$ IRS in 2005, however, no DHS cluster data were available thereafter for comparison.

The island nation of São Tomé and Príncipe, and Bioko Island of Equatorial Guinea also reported widespread IRS activities. In São Tomé and Príncipe, an IVM programme was initiated by the Ministry in 2003 which included IRS, space spraying and larviciding. Between 2005-2007, all districts were targeted with IRS using alphacypermethrin once a year with a reported coverage of $94 \%$ of households. No detailed reports are available, however, large-scale IRS activities were expected to continue until 2009. In Equatorial Guinea, IRS activities have been focused in Bioko Island covering all districts since 2004 using by deltamethrin and/or the 


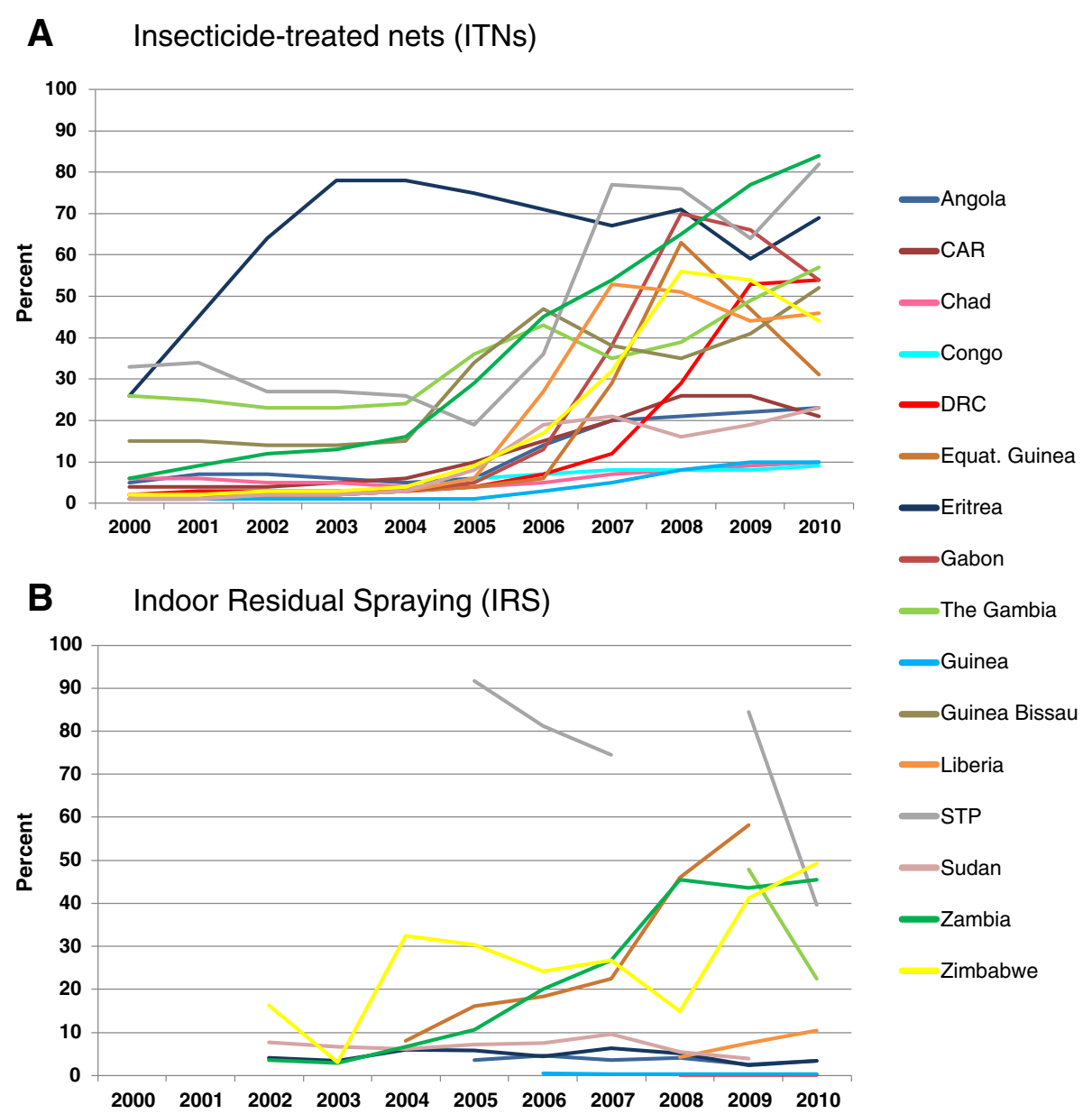

Figure 2 National summaries of the proportion of households with vector control. A. Insecticide-treated nets (ITNs). B. Indoor Residual Spraying (IRS). Note: Data obtained from the Malaria Report 2010, Chapter 4: Vector Control, Table 4.3 and Annex 5.

carbamate, bendiocarb with $72 \%$ to $84 \%$ operational coverage reported.

IRS activities in the other countries report less in terms of geographical coverage and duration, with little data or detailed information available in the public domain. In DRC, IRS has been limited to heath zones where mining companies (extractive industries) are operating, mostly in the Katanga Province. In Sudan, IRS was carried out in targeted irrigated areas and in the Northern, River Nile and Kassala States. In Eritrea, IRS has been implemented in most malarious areas since 2004, initially with blanket coverage and then in selective areas using DDT and the organophosphate, malathion. In 2007, IRS was reported in nine districts across three zones of the country covering an estimated $8 \%$ of the population.

In West Africa, Liberia reported IRS activities in 20072008 in camps for internally displaced persons and refugees, and since 2010 IRS activities have been carried out in selected counties using DDT and pyrethroids. In
Guinea, a survey in 2010 reported 8\% of households had received IRS in the previous 12 months, with the Conakry Region reporting the highest coverage of $19 \%$, while other regions with more than 2\% IRS coverage included the mining areas of Boke, Kankan and Faranah. In The Gambia, a news article highlighted that IRS was introduced in the country in 2008 and implemented by local communities in 2009, and specifically launched in Janjangbureh, Central River Region in 2011, however, no further details or reports are available.

\section{Discussion}

This study provides a broad overview of vector control activities in the 17 African countries that are yet to start, or have only recently started MDA implementation for LF elimination. Overall, the significant scale up of ITNs, and to a lesser extent IRS, is promising, and it is likely that these interventions that reduce malaria transmission $[21,22,42-44]$, have also already impacted on the transmission of $W$. bancrofti in many co-endemic areas. 
Table 2 Urban and rural comparisons of mosquito bed nets and ITNs ownership and usage

\begin{tabular}{|c|c|c|c|c|c|c|c|}
\hline \multirow[t]{2}{*}{ Country } & \multirow[t]{2}{*}{ Year } & \multicolumn{2}{|c|}{$\begin{array}{c}\text { Households (\%) with at least one type } \\
\text { of bed net }\end{array}$} & \multicolumn{2}{|c|}{$\begin{array}{c}\text { Households (\%) with at least } \\
\text { one ITN }\end{array}$} & \multicolumn{2}{|c|}{$\begin{array}{c}\text { Children }(\%)<5 \text { years slept under } \\
\text { any bed net }\end{array}$} \\
\hline & & Urban & Rural & Urban & Rural & Urban & Rural \\
\hline Angola & 2000 & - & - & - & - & 10.8 & 9.6 \\
\hline Angola & 2006 & 34.0 & 31.3 & 29.1 & 25.9 & 19.2 & 22.0 \\
\hline Angola & 2011 & 41.5 & 33.5 & 39.0 & 31.8 & 30.7 & 25.2 \\
\hline CAR & 2000 & - & - & - & - & 48.2 & 19.8 \\
\hline CAR & 2006 & 54.0 & 25.9 & 26.1 & 11.2 & 52.4 & 21.7 \\
\hline Chad & 2004 & - & - & - & - & 77.2 & 61.0 \\
\hline Chad & 2006 & - & - & - & - & 57.5 & 18.6 \\
\hline Congo & 2005 & 82.0 & 68.3 & 8.0 & 8.0 & 76.8 & 59.7 \\
\hline Congo & 2011 & 86.4 & 79.6 & 18.9 & 39.7 & 83.8 & 76.8 \\
\hline DRC & 2001 & - & - & - & - & 15.0 & 10.3 \\
\hline DRC & 2007 & 37.8 & 21.5 & 12.4 & 7.1 & 26.0 & 14.3 \\
\hline Equat. Guinea & - & - & - & - & - & - & - \\
\hline Eritrea & 2002 & 28.3 & 37.3 & - & - & 14.3 & 11.0 \\
\hline Gabon & 2000 & - & - & - & - & - & - \\
\hline The Gambia & 2000 & - & - & - & - & 45.4 & 35.8 \\
\hline The Gambia & 2005 & 48.5 & 69.6 & 34.0 & 64.0 & 54.6 & 67.6 \\
\hline Guinea & 2005 & 27.5 & 26.5 & 1.0 & 0.3 & 15.7 & 11.0 \\
\hline Guinea-Bissau & 2000 & - & - & - & - & 74.7 & 63.4 \\
\hline Guinea-Bissau & 2006 & 81.5 & 77.8 & 34.5 & 48.9 & 79.9 & 70.5 \\
\hline Liberia & 2007 & 31.3 & 29.9 & - & - & - & - \\
\hline Liberia & 2009 & 44.5 & 52.7 & 42.0 & 51.8 & 25.6 & 28.2 \\
\hline STP & 2000 & - & - & - & - & 60.4 & 27.1 \\
\hline STP & 2006 & 58.4 & 37.3 & 44.1 & 25.4 & 61.8 & 41.0 \\
\hline STP & 2008 & 75.2 & 61.1 & 69.2 & 52.4 & 72.9 & 52.3 \\
\hline Sudan & 2000 & - & - & - & - & 25.8 & 20.6 \\
\hline Zambia & 1999 & - & - & - & - & 8.5 & 4.7 \\
\hline Zambia & 2001 & 34.9 & 23.4 & 16.1 & 12.4 & 21.9 & 13.7 \\
\hline Zambia & 2007 & 64.3 & 64.4 & 52.6 & 53.7 & 35.0 & 32.8 \\
\hline Zambia & 2008 & 66.2 & 73.6 & 58.8 & 63.9 & 42.8 & 49.3 \\
\hline Zimbabwe & 2005 & 34.4 & 12.8 & 11.0 & 7.2 & 16.1 & 3.2 \\
\hline Zimbabwe & 2010 & 46.9 & 38.2 & 23.2 & 31.6 & 18.8 & 11.6 \\
\hline
\end{tabular}

Note: Data are based on DHS, MIS, MIC national survey reports available between 2000 and 2010.

However, monitoring their impact will be critical, and it may be more efficient and cost effective for the new LF Programmes to develop formal links with national malaria control programmes and include IVM as one of their key intervention strategies [32]. A recent review has highlighted several examples of IVM carried out in a range of ecological settings [9], which suggests that this integrated approach could be successful in Africa where the main vectors of malaria and LF are similar Anopheles species, and transmission may coincide [10,11,45-48]. In order to achieve this, it is critical that countries take advantage of the current funding available for malaria, as resources may be declining and the window of opportunity for vector control may be closing in the near future.

The reason for the variation in vector control coverage across the different countries may be due to a number of factors including the geographical size (e.g. São Tomé and Príncipe - small islands), and the relative wealth and political stability of a country (e.g. DRC, Guinea, Angola, Zimbabwe - post conflict) [14]. It may also be related to whether a country has an established and active malaria control programme (e.g. The Gambia - traditional high net coverage, Eritrea - high bed net coverage) [49-53], or 


\section{A Mosquito bed nets (any type)}

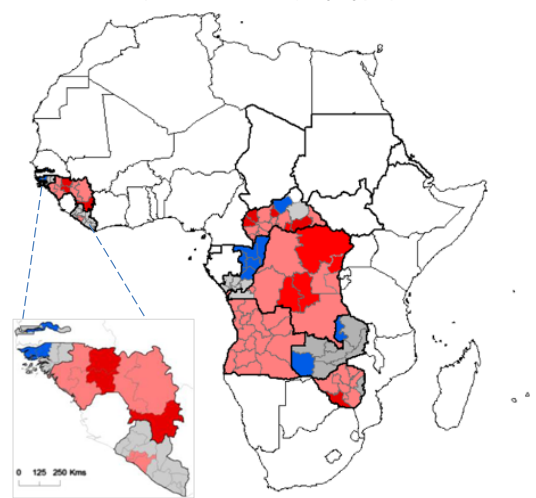

B Insecticide-treated nets (ITNs)

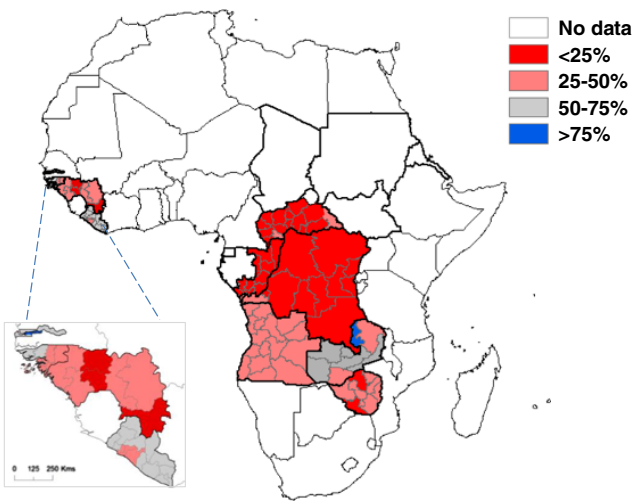

Figure 3 Sub-national distribution of households in possession of at least one bed net and at least one insecticide-treated net (ITN). A. mosquito nets (any type). B. Insecticide-treated nets (ITN). Note: Maps based on data from the following survey reports in Angola (MIS 2006-07), CAR (MICS 2006), Congo (DHS 2005), DRC (DHS 2007), The Gambia (MICS 2005-06), Guinea (DHS 2005), Guinea Bissau (MICS 2006), Liberia (MIS 2009), São Tomé and Príncipe (DHS 2008-09), Zambia (MICS 2008) and Zimbabwe (DHS 2005-06).

has received substantial funding for malaria control from the government and international donors and particularly the Global Fund (e.g. Zambia - significant support from World Bank) [35,36]. These factors are complex and interacting, and how the GPELF can use this information to take full advantage of the increasing scale up of ITN and IRS activities, needs to be considered in the context of the LF endemicity and programmatic capacity of each country, as it can vary considerably $[1,13]$.
It is possible that a number countries such as The Gambia, Eritrea and São Tomé and Príncipe may not need to develop a LF Elimination Programme or implement MDA at all, as they are small, politically stable, have established active malaria control programmes, relatively high bed net coverage and shown limited or no evidence of LF transmission in the past decade. While The Gambia has historical evidence of high LF transmission [54-56], it also has a long history of large scale bed net distribution

\section{Central Southern Africa}

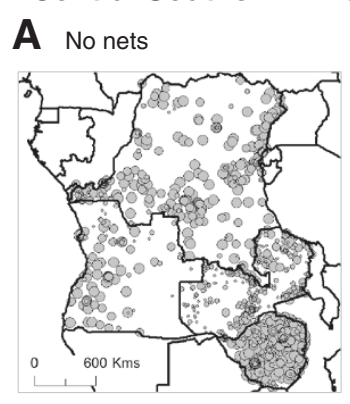

B One net (any type)

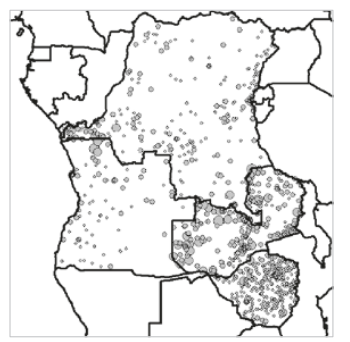

\section{West Africa}

D No nets

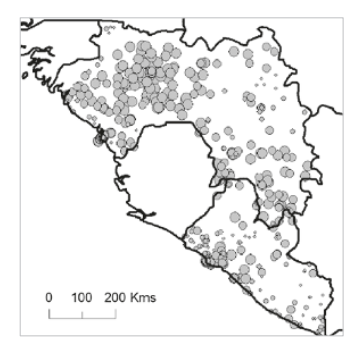

E One net (any type)

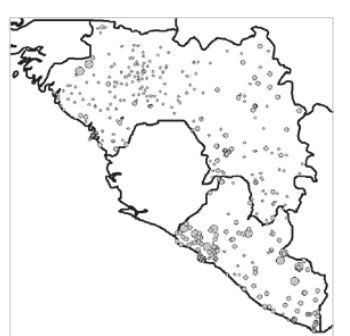

C Two nets (any type)

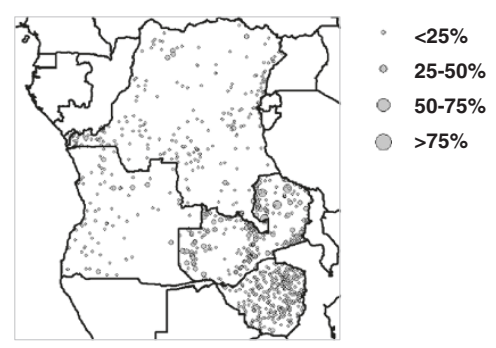

Figure 4 Proportion of households per cluster with bed nets (any type). Central Southern Africa: A. No net. B. One net. C. Two nets. West Africa: D. No net. E. One net F. Two nets. 


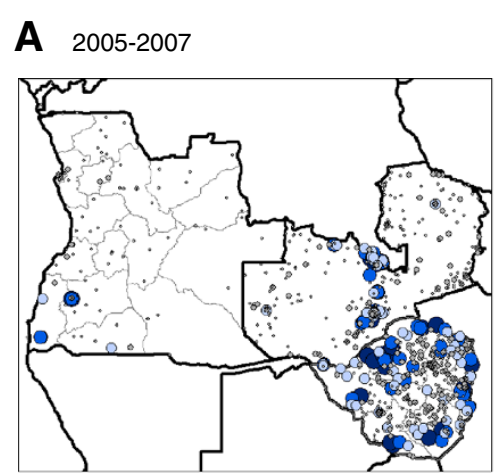

\section{B $2010-2011$}

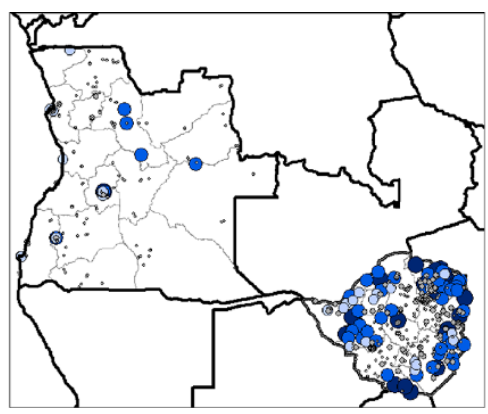

$\%$

- 0

- $<25 \%$

25-50\%

- $50-75 \%$

$>75 \%$

Figure 5 Percentage of households reporting indoor residual spraying (IRS) activities. A. 2005-2007. B. 2010-2011. Notes: Maps based on geo-referenced cluster data collected in Angola (2007, 2011), Zambia (2007), and Zimbabwe $(2005,2010)$.

[52,53], and recent reports suggest that LF is no longer a public health problem (unpublished data). Eritrea has little historical evidence $[8,56]$, has no current data on LF, as programmatic mapping has not started [1], but has a successful vector control programme [49-51]. In São Tomé and Príncipe, historical reports indicate disease presence [56], and recent IVM activities are likely to have impacted transmission [35-41,49]. Therefore, it may be more appropriate to assess these countries for the interruption of transmission using the new Transmission Assessment Survey (TAS) developed by WHO $[57,58]$. Recently, WHO reassessed nine other countries and compiled sufficient evidence to reclassify them as non-endemic, thereby reducing the global number of endemic countries to 73 [59]. A similar assessment using TAS as a tool to verify the lack of transmission in The Gambia, Eritrea and São Tomé and Príncipe may help 'shrink the map', as well as contribute to considerable cost savings. Similarly, on Bioko Island, Equatorial Guinea the use of ivermectin in onchocerciasis control together with a high net and IRS use will have been likely to have an additive impact [60].

Zambia is another country with a well established vector control programme with relatively high bed net coverage, and some IRS activities, which also could have impacted on LF transmission [37,41,49,61,62]. However, in Zambia the LF Programme recently finalised baseline mapping and found two thirds of the population at risk of LF. Overall antigen prevalence rates were low $\leq 10 \%$, except in a few selected regions of the country (unpublished data). The first MDA is due to start in early 2013 and together with the ongoing vector control activities, the LF Programme could see a significant reduction in transmission in most regions of the country within a few years. The only concern to note is that there is already widespread insecticide resistance found in several Anopheles species across the country and different strategies to overcome this are currently being developed [41,63].
The extent to which insecticide resistance prevents ITNs and IRS from being effective is not known, especially in relation to LF transmission. However, given the increasing geographical spread of resistance to multiple classes of insecticide across Africa [64-68], there seems to be another small window of opportunity to maximise the full potential of these alternative strategies. Alarmingly, almost all of the 17 countries have already reported some degree of insecticide resistance to one of the main classes of insecticides, in one of the main Anopheles species responsible for malaria transmission. The scope of this problem is yet to be fully determined, however, resistance monitoring is becoming increasingly important among international stakeholders such as PMI [41], and the development of publicly accessible up-to-date databases and maps, including the new IR Mapper [67,68], will help to assess the situation over time and space along with other programmatic activities [69-71]. This is particularly important given the limited availability of vector control tools and the fact that new products will not be available for some years [72]. It is also not know what effect insecticide resistance will have on filarial worm development in Anopheles mosquitoes, as in Culex, highly elevated esterases involved in insecticide resistance were found to inhibit development of microfilariae of W.bancrofti in a study in Sri Lanka [73].

The countries facing the greatest challenges are those that have endured conflict and civil unrest, and have among the lowest coverage of vector control interventions such as Congo, Guinea, and DRC [15,35-41]. New LF programmes in these countries are establishing themselves, with significant barriers related to the lack of public infrastructure, transport networks and trained health personnel. Malaria control programmes face similar constraints despite significantly more funding available for vector control $[35,36,40,41]$. In large countries such as DRC, significant geographical factors have been found to contribute to low bed net coverage in remote, rural areas [15], which suggests that alternative distribution 
methods are needed, especially where LF may be coendemic with $L$. loa and ITNs are one of the main recommended strategies by WHO [20]. Increased efforts to boost vector control coverage in high risk L. loa coendemic areas is critical, especially as potential alternative strategies such as twice a year albendazole have to go to scale whilst the use of doxycycline an anti-Wolbachia macrofilaricide or adult sterilising agent [74-76], has yet to be recommended or available for distribution without medical supervision.

The use of the established and extensive network of community drug distributors working for the African Programme for Onchocerciasis Control (APOC) in eight of the 17 countries may be an entry point to increase ITN distributions as has been demonstrated in Nigeria $[77,78]$. This will benefit both the LF and malaria programmes, and provide new opportunities for onchocerciasis programmes which may be scaling down due to their success as they move towards the elimination of transmission of Onchocerca volvulus [79,80]. Already many LF Elimination Programmes across Africa use the community-directed treatment with ivermectin (CDTi) strategy developed by APOC, as a platform to distribute MDA [1]. It seems sensible to extend this to include ITNs and other interventions in the remote hard-to-reach, co-endemic areas where CDTi already operates [78,81]. Finer scale mapping, using the micro-stratification overlap mapping (MOM) approach, could be used to identify the populations most at risk, so that ITNs distributions can be specifically targeted [19]. However, more collaboration, communication and coordination between the various NTD and malaria vector-borne disease control programmes is important and becoming an international priority.

\section{Conclusions}

This study highlights that although many African countries are behind with initiating MDA, and populations remain at risk, the continued global commitment and financial support and the expansion of insecticide-based vector control activities, is promising. The scale-up of these interventions is unprecedented and provides a unique opportunity to impact significantly on two major vector-borne diseases in Africa. It is not beyond the scope of GPELF in reaching its target of global elimination by 2020, however, more evidence-based data are needed to firmly establish the association between malaria vector control activities and the decline in the indicators of transmission of LF, and monitoring and evaluating the impact of these activities over the next decade will be critical to its success.

\section{Competing interests}

The authors declare that they have no competing interests.

\section{Authors' contributions}

LKH and MJB conceived the idea for the study. LKH identified data sources, developed the study design and collated, mapped and analysed the data. DHM and MJB contributed to the interpretation of results. LKH wrote the first draft, and all authors contributed to and read the final version of the manuscript.

\section{Acknowledgements}

We acknowledge Dr Kazuyo Ichimori from the World Health Organization $(\mathrm{WHO})$ for discussions on integrated vector management to control malaria and lymphatic filariasis. The study was funded from a grant from the Department for International Development (DFID) and GlaxoSmithKline (GSK) for research on the elimination of lymphatic filariasis.

Received: 22 December 2012 Accepted: 5 February 2013

Published: 22 February 2013

\section{References}

1. World Health Organization: Progress report 2000-2009 and strategic plan 2010-2020 of the global programme to eliminate lymphatic filariasis: halfway towards eliminating lymphatic filariasis. Geneva: WHO/HTM/NTD/PCT/2010.6; 2010.

2. World Health Organization: Global programme to eliminate lymphatic filariasis: progress report, 2011. Wkly Epidemiol Rec 2012, 87:346-356.

3. Molyneux DH, Nantulya VM: Linking disease control programmes in rural Africa: a pro-poor strategy to reach Abuja targets and millennium development goals. BMJ 2004, 328:1129-1132.

4. Molyneux DH, Hotez PJ, Fenwick A, Newman RD, Greenwood B, Sachs J: Neglected tropical diseases and the Global Fund. Lancet 2009, 373:296-299.

5. Manga L: Vector-control synergies, between 'Roll Back Malaria' and the Global Programme to Eliminate Lymphatic Filariasis, in the African Region. Ann Trop Med Parasitol 2002, 96(suppl 2):S129-S132.

6. Bockarie MJ, Pedersen EM, White GB, Michael E: Role of vector control in the global program to eliminate lymphatic filariasis. Annu Rev Entomol 2009, 54:469-487. Review.

7. Lindsay SW, Thomas CJ: Mapping and estimating the population at risk from lymphatic filariasis in Africa. Trans R Soc Trop Med Hyg 2000, 94:37-45.

8. Sasa M: Human Filariasis - a Global Survey of Epidemiology and Control. Baltimore, Maryland: University Park Press; 1976.

9. van den Berg H, Kelly-Hope LA, Lindsay SW: Malaria and lymphatic filariasis: the case for integrated vector management. Lancet Infect Dis 2013, 13:89-94.

10. de Souza DK, Koudou B, Kelly-Hope LA, Wilson MD, Bockarie MJ, Boakye DA Diversity and transmission competence in lymphatic filariasis vectors in West Africa, and the implications for accelerated elimination of Anopheles-transmitted filariasis. Parasit Vectors 2012, 5:259.

11. Manguin S, Bangs MJ, Pothikasikorn J, Chareonviriyaphap T: Review on global co-transmission of human Plasmodium species and Wuchereria bancrofti by Anopheles mosquitoes. Infect Genet Evol 2009, 10:159-177.

12. Raghavan NG: The vectors of human infections by Wuchereria species in endemic areas and their biology. Bull World Health Organ 1961, 24:177-195.

13. Addiss D: Global Alliance to Eliminate Lymphatic Filariasis. The 6th Meeting of the Global Alliance to Eliminate Lymphatic Filariasis: A halftime review of lymphatic filariasis elimination and its integration with the control of other neglected tropical diseases. Parasit Vectors 2010, 3:100.

14. UNDP: International Human Development Indicators. Available at: http:// hdr.undp.org/en/statistics/.

15. Stanton M, Bockarie MJ, Kelly-Hope LA: Geographical Factors Affecting Bed Net Ownership, a Tool for the Elimination of Anopheles-Transmitted Lymphatic Filariasis in Hard-to-Reach Communities. PLoS One 2013, 8:e53755.

16. Zouré HG, Wanji S, Noma M, Amazigo UV, Diggle PJ, Tekle AH, Remme JH: The geographic distribution of Loa loa in Africa: results of large-scale implementation of the Rapid Assessment Procedure for Loiasis (RAPLOA). PLoS Negl Trop Dis 2011, 5:e1210.

17. Boussinesq M: Loiasis. Ann Trop Med Parasit 2006, 100:715-731. 
18. Gardon J, Gardon-Wendel M, Demanga ND, Kamgno J, Chippaux JP, et al: Serious reactions after mass treatment of onchocerciasis with ivermectin in an area endemic for Loa loa infection. Lancet 1997, 1997(350):18-22.

19. Kelly-Hope LA, Thomas BC, Bockarie MJ, Molyneux DH: Lymphatic filariasis in the Democratic Republic of Congo; micro-stratification overlap mapping (MOM) as a prerequisite for control and surveillance. Parasit Vectors 2011, 4:178.

20. World Health Organization: Provisional strategy for interrupting Lymphatic filariasis transmission in loiasis-endemic countries, Report of the meeting on lymphatic filariasis, malaria and integrated vector management. Accra, Ghana, 5-9 March 2012. 2012. WHO/HTM/NTD/PCT/2012.6.

21. Lengeler $C$ : Insecticide-treated bed nets and curtains for preventing malaria. Cochrane Database Syst Rev 2004, (2):Art. No CD000363. doi:10.1002/14651858.CD000363.pub2

22. Pluess B, Tanser FC, Lengeler C, Sharp BL: Indoor residual spraying for preventing malaria. Cochrane Database Syst Rev 2010, (4):Art. No: CD006657. doi:10.1002/14651858.CD006657.pub2.

23. Ashton RA, Kyabayinze DJ, Opio T, Auma A, Edwards T, Matwale G, Onapa A, Brooker S, Kolaczinski JH: The impact of mass drug administration and long-lasting insecticidal net distribution on Wuchereria bancrofti infection in humans and mosquitoes: an observational study in northern Uganda. Parasit Vectors 2011, 4:134

24. Emukah E, Graves PM, Mosher AW, Rakers L, Miri E, Chidiebere N, Kenrick N, Josephine O, Njideka OT, Richards FO: Long lasting insecticidal nets alone can reduce transmission of lymphatic filariasis in south east Nigeria, Abstract Book American Society of Tropical Medicine and Hygiene 58th Annual Meeting: November18-22, 2009, Washington DC.

25. Bockarie MJ, Tavul L, Kastens W, Michael E, Kazura JW: Impact of untreated bednets on prevalence of Wuchereria bancrofti transmitted by Anopheles farauti in Papua New Guinea. Med Vet Entomol 2002, 16:116-119.

26. Pedersen EM, Mukoko DA: Impact of insecticide-treated materials on filaria transmission by the various species of vector mosquito in Africa. Ann Trop Med Parasitol 2002, 96(Suppl 2):S91-S95.

27. Bøgh C, Pedersen EM, Mukoko DA, Ouma JH: Permethrin-impregnated bednet effects on resting and feeding behaviour of lymphatic filariasis vector mosquitoes in Kenya. Med Vet Entomol 1998, 12:52-59.

28. Burkot TR, Garner P, Paru R, et al: Effects of untreated bed nets on the transmission of Plasmodium falciparum, $P$. vivax and Wuchereria bancrofti in Papua New Guinea. Trans R Soc Trop Med Hyg 1990, 4:773-779.

29. Prybylski D, Alto WA, Mengeap S, Odaibaiyue S: Introduction of an integrated community-based bancroftian filariasis control program into the Mt Bosavi region of the Southern Highlands of Papua New Guinea. PNG Med J 1994, 37:82-89.

30. Webber R: Eradication of Wuchereria bancrofti through vector control. Trans R Soc Trop Med Hyg 1979, 76:722-724.

31. Webber $\mathrm{RH}$ : The natural decline of Wuchereria bancrofti infection in a vector control situation in the Solomon Islands. Trans $R$ Soc Trop Med Hyg 1977, 71:396-400.

32. World Health Organization: WHO position statement on integrated vector management to control malaria and lymphatic filariasis. Wkly Epidemiol Rec 2011, 86:121-127.

33. Wanji S, Takougang I, Yenshu EV, Meremikwu M, Enyong P, Braide E, et al: Rapid Assessment Procedures for Loiasis. Report of a Multi-centre study, UNDP/ World Bank/WHO Special Programme for Research and Training in Tropical Diseases TDR/IDE/RP/RAPL/01.12001.

34. Kelly-Hope LA, Bockarie MJ, Molyneux DH: Loa loa ecology in central Africa: role of the Congo River system. PLoS Negl Trop Dis 2012, 6:e1605.

35. World Health Organization: World Malaria Report 2010, WHO Global Malaria Programme 2010. Available at [http://www.who.int/malaria/ world malaria report 2010/en/index.html]

36. World Health Organization: World Malaria Report 2011, WHO Global Malaria Programme 2011. Available at [http://www.who.int/malaria/ world_malaria_report_2011/en/]

37. World Health Organization: Implementation of Indoor Residual Spraying of Insecticides for Malaria Control in the World Health Organization African Region Report. World Health Organization for Africa; 2007. Available at http://www.afro. who.int/en/clusters-a-programmes/dpc/malaria/mal-publications.html.

38. MEASURE DHS: Demographic and Health Surveys. Available at [http:// www.measuredhs.com/]

39. UNICEF: Statistics and Monitoring. Multiple Indicator Cluster Surveys (MICS)., [http://www.unicef.org/statistics/index_24302.html]
40. Roll Back Malaria: Malaria Country Facts., [http://www.rbm.who.int/]

41. President's Malaria Initiative: Malaria Operational Plans. [http://www.pmi. gov/index.html]

42. O'Meara WP, Mangeni JN, Steketee R, Greenwood B: Changes in the burden of malaria in sub-Saharan Africa. Lancet Infect Dis 2010, 10:545-555.

43. Shaukat AM, Breman JG, McKenzie FE: Using the entomological inoculation rate to assess the impact of vector control on malaria parasite transmission and elimination. Malaria J 2010, 9:122.

44. Mabaso ML, Sharp B, Lengeler C: Historical review of malarial control in southern African with emphasis on the use of indoor residual housespraying. Trop Med Int Health 2004, 9:846-856.

45. Sinka ME, Bangs MJ, Manguin S, Coetzee M, Mbogo CM, et al: The dominant Anopheles vectors of human malaria in Africa, Europe and the Middle East: occurrence data, distribution maps and bionomic précis. Parasit Vectors 2010, 3:117.

46. Kelly-Hope LA, McKenzie FE: The multiplicity of malaria transmission: a review of entomological inoculation rate measurements and methods across sub-Saharan Africa. Malaria J 2009, 8:19.

47. Muirhead-Thomson RC: Inter-relations between filarial and malarial infections in Anopheles gambiae. Nature 1953, 172:352-353.

48. Njenga SM, Mwandawiro CS, Wmae CN, Mukoko DA, Omar AA, et al: Sustained reduction in prevalence of lymphatic filariasis infection in spite of missed rounds of mass drug administration in an area under mosquito nets for malaria control. Parasit Vectors 2011, 4:90.

49. Newman RD: Malaria control beyond 2010. BMJ 2010, 340:c2714.

50. Yukich JO, Zerom M, Ghebremeskel T, Tediosi F, Lengeler C: Costs and cost-effectiveness of vector control in Eritrea using insecticide-treated bed nets. Malaria J 2009, 8:51.

51. Mufunda J, Nyarango P, Usman A, Gebremeskel T, Mebrahtu G, Ogbamariam A, Kosia A, Ghebrat Y, Gebresillosie S, Goitom S, Araya E, Andemichael G, Gebremichael A: Roll back malaria - an African success story in Eritrea. S Afr Med J 2007, 97:46-50.

52. Cham MK, D'Alessandro U, Todd J, Bennett S, Fegan G, Cham BA, Greenwood BM: Implementing a nationwide insecticide-impregnated bednet programme in The Gambia. Health Policy Plann 1996, 11:292-298.

53. Snow RW, Lindsay SW, Hayes RJ, Greenwood BM: Permethrin-treated bed nets (mosquito nets) prevent malaria in Gambian children. Trans $R$ Soc Trop Med Hyg 1988, 82:838-842.

54. McFadzean JA: Filariasis in Gambia and Casamance, West Africa. Trans $R$ Soc Trop Med Hyg 1954, 48:267-273.

55. McGregoria IA, Hawking F, Smith DA: The control of filariasis with hetrazan; a field trial in a rural village (Keneba) in the Gambia. Br Med $J$ 1952, 2:908-911.

56. Hawking F: The distribution of human filariasis throughout the world. Part III. Africa. World Health Organization; 1977. WHO/FIL/74.124.

57. Work Health Organization: Monitoring and epidemiological assessment of mass drug administration in the global programme to eliminate lymphatic filariasis: a manual for national elimination programmes. 2010, WHO/HTM/NTD/PCT/2011.4

58. Work Health Organization: Transmission assessment surveys in the Global Programme to Eliminate Lymphatic Filariasis: WHO position statement. Wkly Epidemiol Rec 2012, 87:478-482.

59. World Health Organization: Global programme to eliminate lymphatic filariasis. Wkly Epidemiol Rec 2010, 85:365-372.

60. Kyelem D, Medlock J, Sanou S, Bonkoungou M, Boatin B, Molyneux DH: Short communication: impact of long-term (14 years) bi-annual ivermectin treatment on Wuchereria bancrofti microfilaraemia. Trop Med Int Health 2005, 10:1002-1004.

61. Chizema-Kawesha E, Miller JM, Steketee RW, Mukonka VM, Mukuka C, Mohamed AD, Miti SK, Campbell CC: Scaling Up Malaria Control in Zambia: Progress and Impact 2005-2008. Am J Trop Med Hyg 2010, 83:480-488.

62. Steketee RW, Sipilanyambe N, Chimumbwa J, Banda JJ, Mohamed A, Miller J, Basu S, Miti SK, Campbell CC: National malaria control and scaling up for impact: the Zambia experience through 2006. Am J Trop Med Hyg 2008, 79:45

63. Chanda E, Hemingway J, Kleinschmidt I, Rehman AM, Ramdeen V, Phiri FN, Coetzer S, Mthembu D, Shinondo CJ, Chizema-Kawesha E, Kamuliwo M, Mukonka V, Baboo KS, Coleman M: Insecticide Resistance and the Future of Malaria Control in Zambia. PLoS One 2011, 6:e24336. 
64. Ranson H, N'guessan R, Lines J, Moiroux N, Nkuni Z, Corbel V: Pyrethroid resistance in African anopheline mosquitoes: what are the implications for malaria control? Trends Parasitol 2011, 27:91-98.

65. African Network for Vector Resistance: Atlas of insecticide resistance in malaria vectors of the WHO African region. Harare: World Health Organization Regional Office for Africa; 2005.

66. Yewhalaw D, Wassie F, Steurbaut W, Spanoghe P, van Bortel W, Denis L, Tessema D, Getachew Y, Coosemans M, Duchateau L, et al: Multiple Insecticide Resistance: An Impediment to Insecticide-Based Malaria Vector Control Program. PLoS One 2011, 6:e16066.

67. Mapper IR: Mapping insecticide resistance in malaria vectors. [http:// www.irmapper.com/]

68. VectorBase: Bioinformatics Resource for Invertebrate Vectors of Human Pathogens. IRBase., [https://www.vectorbase.org/content/irbase]

69. Kelly-Hope L, Ranson H, Hemingway J: Lessons from the past: managing insecticide resistance in malaria control and eradication programmes. Lancet Infect Dis 2008, 8:387-389.

70. Insecticide Resistance Action Committee (IRAC): Prevention and management of insecticide resistance in vectors of public health importance. [http://www.irac-online.org/teams/public-health/]

71. Bass C, Nikou D, Vontas J, Donnelly MJ, Williamson MS, Field LM: The Vector Population Monitoring Tool (VPMT): High-Throughput DNA-Based Diagnostics for the Monitoring of Mosquito Vector Populations. Malar Res Treat 2010, 2010:190434.

72. Hemingway J, Beaty BJ, Rowland M, Scott TW, Sharp BL: The Innovative Vector Control Consortium: improved control of mosquito-borne diseases. Trends Parasitol 2006, 22:308-312.

73. McCarroll L, Paton MG, Karunaratne SHPP, Jayasuryia HTR, Kalpage KSP Hemingway J: Insecticides and mosquito-borne disease. Nature 2000, 407:961-996.

74. Tamarozzi F, Tendongfor N, Enyong PA, Esum M, Faragher B, Wanji S, Taylor MJ: Long term impact of large scale community-directed delivery of doxycycline for the treatment of onchocerciasis. Parasit Vectors 2012, 5:53.

75. Hoerauf A, Pfarr K, Mand S, Debrah AY, Specht S: Filariasis in Africatreatment challenges and prospects. Clin Microbiol Infect 2011, 17:977-985.

76. Wanji S, Tendongfor N, Nji T, Esum M, Che JN, Nkwescheu A, Alassa F, Kamnang G, Enyong PA, Taylor MJ, Hoerauf A, Taylor DW: Communitydirected delivery of doxycycline for the treatment of onchocerciasis in areas of co-endemicity with loiasis in Cameroon. Parasit Vectors 2009, 2:39.

77. Blackburn BG, Eigege A, Gotau H, Gerlong G, Miri E, Hawley WA, Mathieu E, Richards F: Successful integration of insecticide-treated bed net distribution with mass drug administration in Central Nigeria. Am J Trop Med Hyg 2006, 75:650-655.

78. The CDI Study Group: Community-directed interventions for priority health problems in Africa: results of a multicountry study. Bull World Health Organ 2010, 88:509-518.

79. Diawara L, Troare M, Badji A, Issan Y, Doumbia K, Goita SF, Konate L, Miunkoro K, Sarr MD, Seck AF, Toe L, Toure S, Remme JHF: Feasibility of onchocerciasis elimination with ivermectin treatment in endemic foci in Africa: first evidence from studies in Mali and Senegal. PLOS Negl Trop Dis 2009, 3:e497.

80. Tekle A, Elhassan E, Isiyaku S, Amazigo UV, Bush S, Noma M, Cousens S, Abiose A, Remme JH: Impact of long-term treatment of onchocerciasis with ivermectin in Kaduna State, Nigeria: first evidence of the potential for elimination in the operational area of the African Programme for Onchocerciasis Control. Parasit Vectors 2012, 5:28.

81. Amazigo UV, Leak SGA, Zoure HGM, Njepuome N, Lusamba-Dikassa PS: Community-driven interventions can revolutionise control of neglected tropical diseases. Trends Parasitol 2012, 28:231-238.

doi:10.1186/1756-3305-6-39

Cite this article as: Kelly-Hope et al:: Can malaria vector control accelerate the interruption of lymphatic filariasis transmission in Africa; capturing a window of opportunity?. Parasites \& Vectors 2013 6:39.

\section{Submit your next manuscript to BioMed Central and take full advantage of:}

- Convenient online submission

- Thorough peer review

- No space constraints or color figure charges

- Immediate publication on acceptance

- Inclusion in PubMed, CAS, Scopus and Google Scholar

- Research which is freely available for redistribution

Submit your manuscript at www.biomedcentral.com/submit
C Biomed Central 